\title{
UCRL-TR-223343
}

LAW RENCE LIVERMORE N A TIO N A L LABORATORY

\section{Material Evaluation Test Series 07, 08A, and 09A}

David Zalk, Carl Ingram, Larry Simmons, Ron Arganbright, Carolyn Koester, Jim Lyle

August 3, 2006 
This document was prepared as an account of work sponsored by an agency of the United States Government. Neither the United States Government nor the University of California nor any of their employees, makes any warranty, express or implied, or assumes any legal liability or responsibility for the accuracy, completeness, or usefulness of any information, apparatus, product, or process disclosed, or represents that its use would not infringe privately owned rights. Reference herein to any specific commercial product, process, or service by trade name, trademark, manufacturer, or otherwise, does not necessarily constitute or imply its endorsement, recommendation, or favoring by the United States Government or the University of California. The views and opinions of authors expressed herein do not necessarily state or reflect those of the United States Government or the University of California, and shall not be used for advertising or product endorsement purposes.

This work was performed under the auspices of the U.S. Department of Energy by University of California, Lawrence Livermore National Laboratory under Contract W-7405-Eng-48. 


\title{
Material Evaluation Test Series (METS) 07, 08A, and 09A
}

\author{
PIs: D. Zalk ${ }^{1}$, L. Simmons ${ }^{2}$, C. Ingram ${ }^{2}$ \\ Co-PIs: R. Arganbright ${ }^{3}$, C. Koester ${ }^{4}, J$. Lyle $^{2}$ \\ ${ }^{1 \cdot}$ HCD, SEP \\ 2. B Div, DNT \\ ${ }^{3}$ MMED \\ ${ }^{4}$ CMS
}

\section{Introduction}

This research effort examines the post-detonation environmental, safety, health and operational aspects of experimental explosive tests with mercury. Specific experimental information is necessary for the evaluation of post-detonation by-products in comparison with those potentially resulting from mercury-bearing material accumulation in biomass accumulation areas, such as landfills, from batteries, electrical switches, thermometers, and fluorescent lights (Lindberg et al 2001). This will assist in determining appropriate abatement techniques for cleaning the work environment and environmental mitigation to determine waste stream components and risk assessment protocol. Determination of the by-products for personal protection equipment and personal exposure monitoring parameters are also part of this experimental work.

\section{Scope and Objectives}

This research is focused on developing an appropriate mercury by-product collection apparatus for separating post-detonation airborne particulate from organic and inorganic mercury vapor for individual component analysis. The experimental detonation occurred within a 314 cubic foot cylindrical firing tank for experimental detonation of up to 500 grams of energetic material. To accomplish individual component analysis, analytical techniques were focused on segregating and analyzing the potential worst-case hazardous component, dimethyl mercury (DMM) (Kulig 1998). Should DMM be created by this experiment, additional experimental design is necessary to mitigate this component for both environmental and personnel acute exposure concerns (Byard et al 1998). By accurately deriving airborne components, both immediately post-shot and during worker clean-up procedures, we can then determine the appropriate response for fugitive emissions and possess the ability to downgrade personal protection equipment to available product that affords a safer alternative for cleaning the firing tank for re-use.

\section{Specific Project Objectives}

1. Create a collection apparatus to determine effectiveness for capturing and accurately analyzing a surrogate material for mercury immediately post-shot.

2. Based on results from the surrogate material, create and perfect a collection apparatus to separate mercury particulate from its organic and inorganic vapor components. 
A. Develop an analytical method for safely, quickly, and accurately determining the presence and amount of DMM from the organic mercury vapor.

B. Develop a protocol to protect the clean-up workers from the potential for DMM exposure and create personal protective clothing to prevent dermal exposure to this acutely toxic component.

Should DMM be detected, develop mitigating procedures to abate or eliminate the DMM component from the waste stream and reduce health risks from cleaning the firing tank.

\section{Experimental Methods}

\section{METS 07; Develop collection apparatus for surrogate material}

The experimental detonation will occur within a 314 cubic foot cylindrical firing tank for experimental detonation of up to 500 grams of energetic material. This firing tank was used to determine the METS testing for beryllium metal on the B850 firing table (Zalk 2002). This tank was transferred to the B812 firing table to enable this extended experimental process (Figure 1). Three devices were built identically to evaluate material to be exposed to explosives shock and thermal effects. The METS 07 device placed a lead surrogate in place of the mercury to prove out the sampling technique and its collection apparatus. The initial experimental collection system (Figures 2 and 3) utilized a $41 \mathrm{~mm}$ Whatman $0.8 \mu \mathrm{m}$ mixed cellulose ester filter to separate particulate from the vapor (Zalk 2001) (Zalk et al 2003). The vapor was collected in two 1-liter stainless steel sample bottles by drawing a measured volume from a vacuum system. The sample bottles were transferred to $\mathrm{B} 132 \mathrm{~N}$ for organic component analysis. This analysis was achieved by placing Solid Phase Micro-Extraction (SPME) fibers into the bottle for static adsorption followed by a Gas Chromatograph Mass Spectrometry (GC/MS) analysis (Koziel and Pawliszyn 2001).

Figure 1. Firing tank configuration

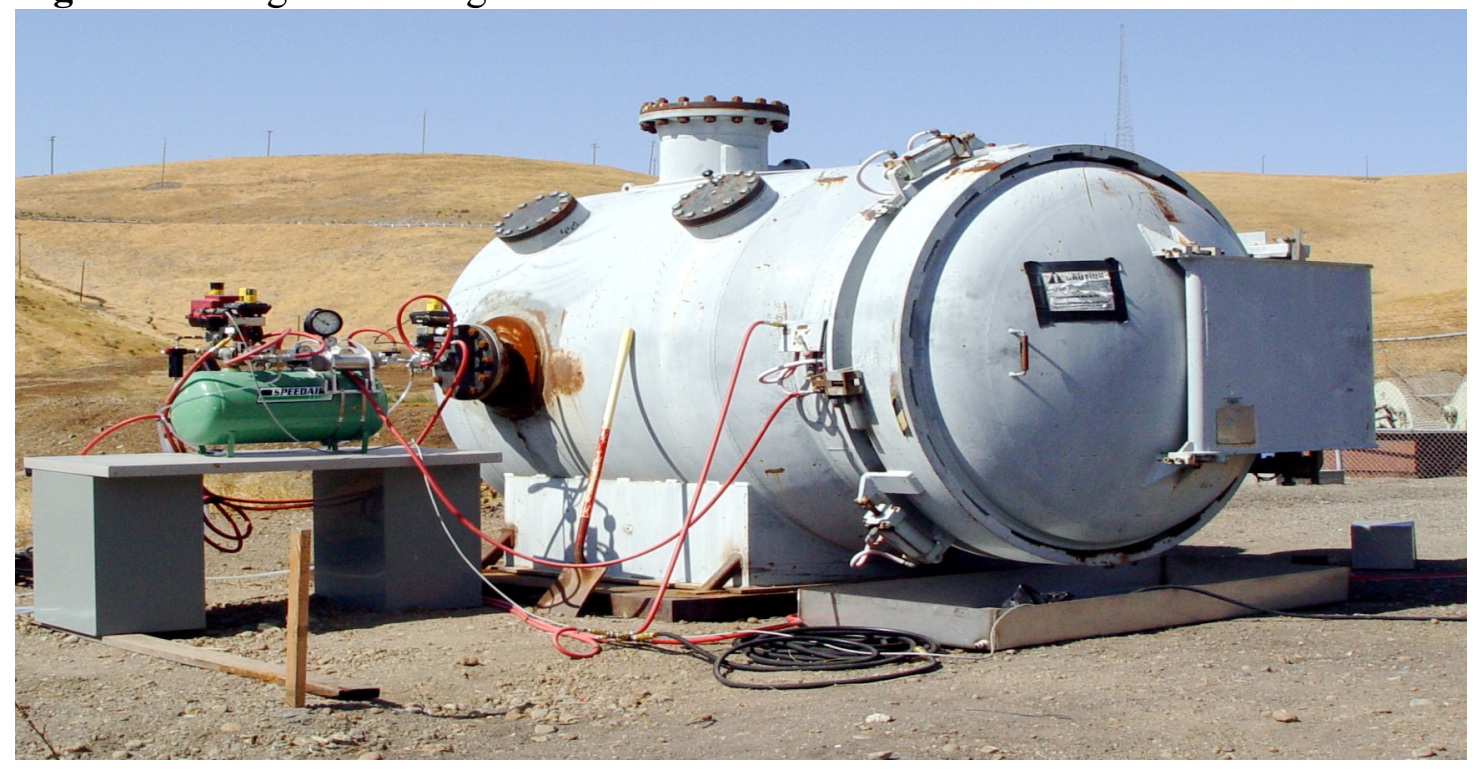


UCRL-TR-223343

Figure 2. Schematic of METS 07 collection apparatus

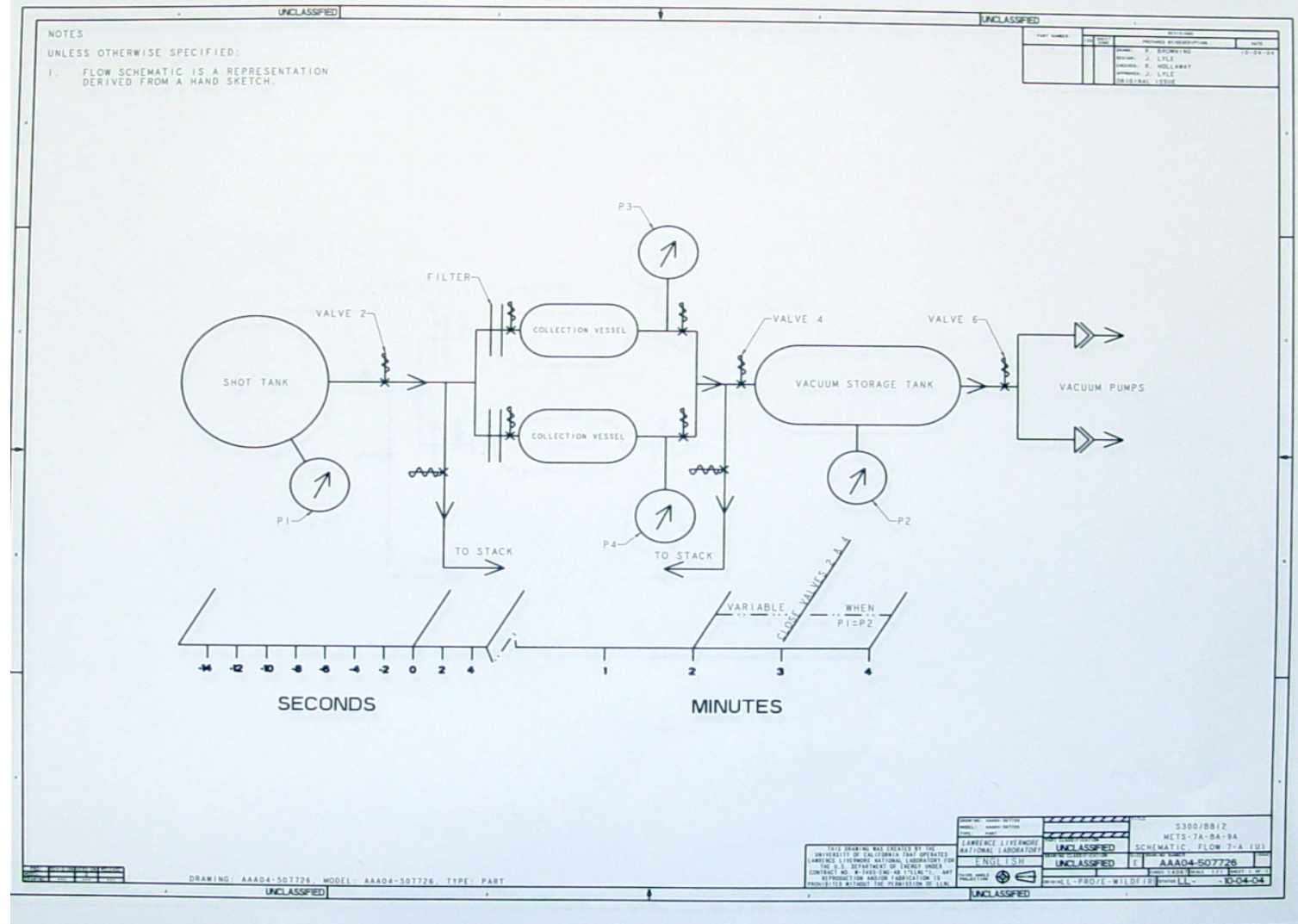

Figure 3. Photograph of METS 07 collection apparatus

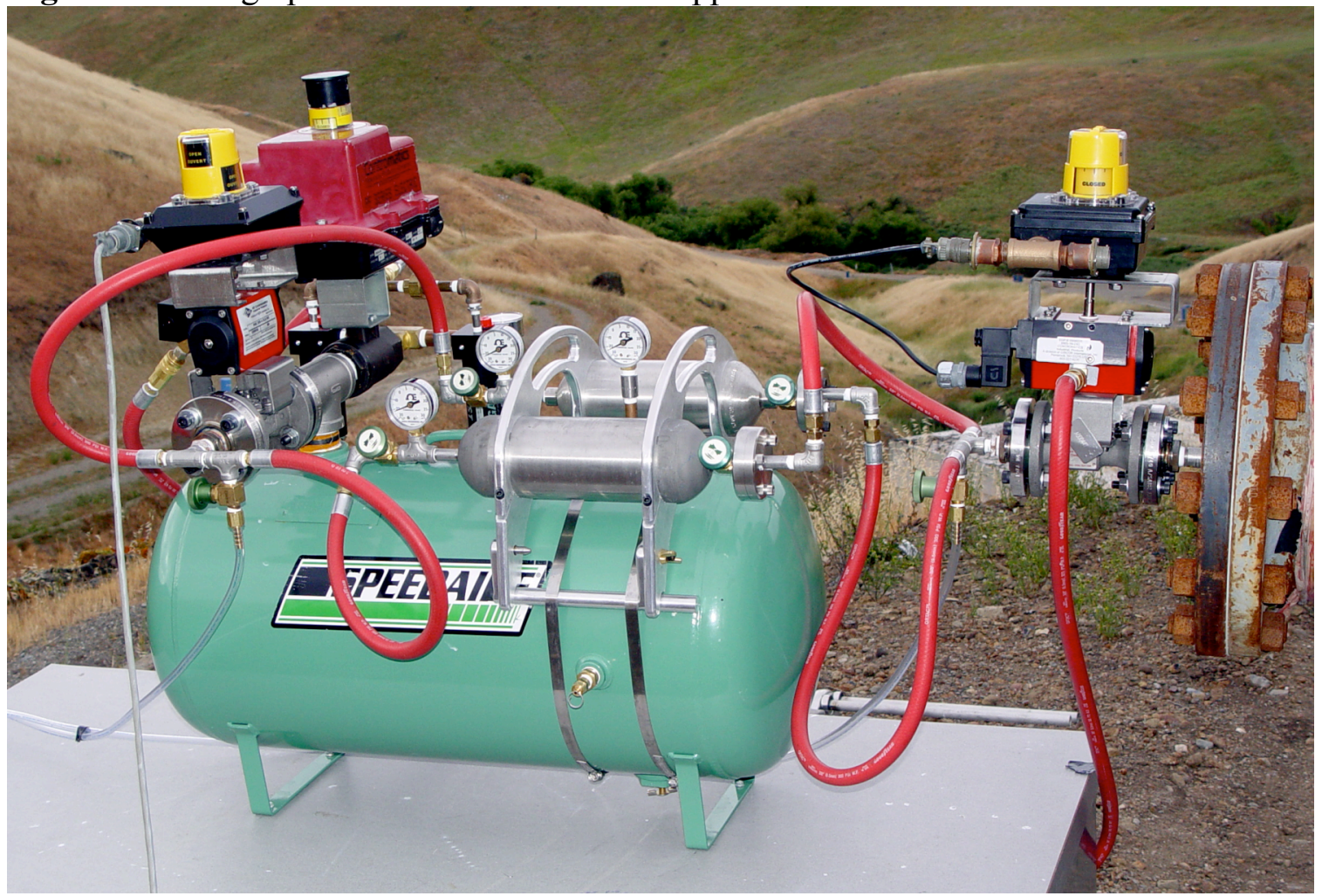




\section{METS 08A; Develop a mercury collection system and DMM analytical techniques}

After cleaning out the firing tank from METS 07, a new sample collection apparatus was re-designed for the mercury component. The second experimental device, now with mercury in place, was used. The devices for both METS 08A and 09A were created identically (Figures 4 and 7). During the experimental design for METS 08A, numerous meetings were held to evaluate our hypothesis that the potential for creating organic mercury vaporous components did exist, including the highly toxic DMM byproduct. Analytical chemists determined from the existing device's design, there was virtually no potential for creating organic mercury vapor due to the insufficient amount of carbon material available. However, they agreed that we should still be looking for, and appropriately analyzing for, the organic component to ensure it was not created.

To achieve this, the METS 07 sampling apparatus was modified for the mercury component. The sampling train was initiated with the same Whatman particulate filters. However, modifications were made for including DMM collection traps, Carbosorb tubes, and inorganic mercury vapor collection traps, with hopcalite tubes. In between the mercury traps were the 1-liter stainless steel bottles fitted for the SPME fibers within each of the two bottles (Figures 5 and 6). The same rate and volume of air was pulled through the sampling apparatus and the mercury collection medium. The SPME analytical method places a SPME fiber within the bottle for two hours of static adsorption of potential DMM component. The SPME fiber itself is then immediately transferred to B132N for GC/MS analysis (microgram detection limit) while the DMM traps were sent off-site for Cold Vapor Atomic Absorption Spectrometry (CVAAS) analysis (nanogram detection limit) using an established, highly sensitive method for DMM analysis.

Figure 4. Photograph of METS 08A and 09A assembly.

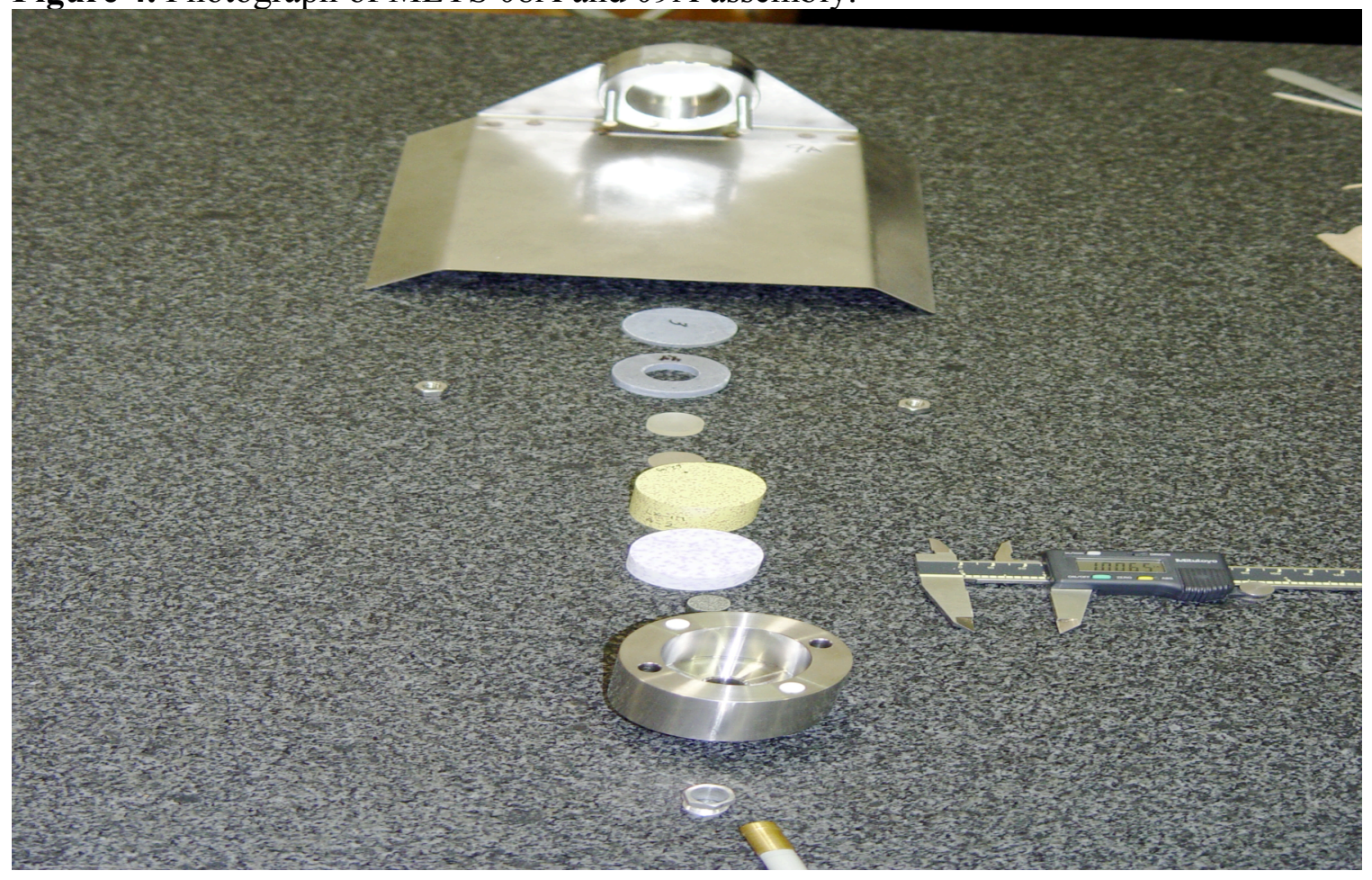


UCRL-TR-223343

Figure 5. Schematic of METS 08A collection apparatus.

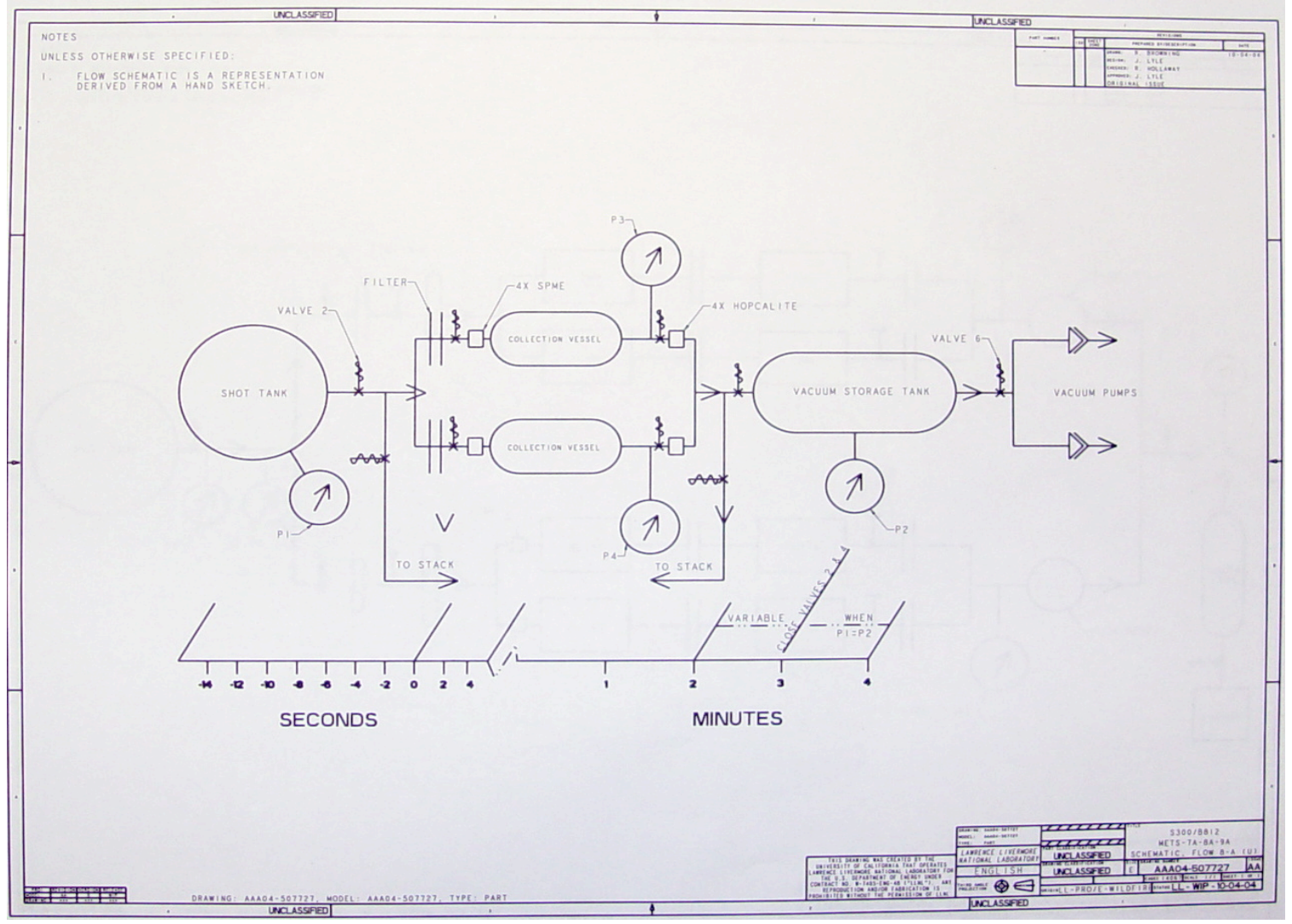

Figure 6. Photograph of METS 08A collection apparatus.

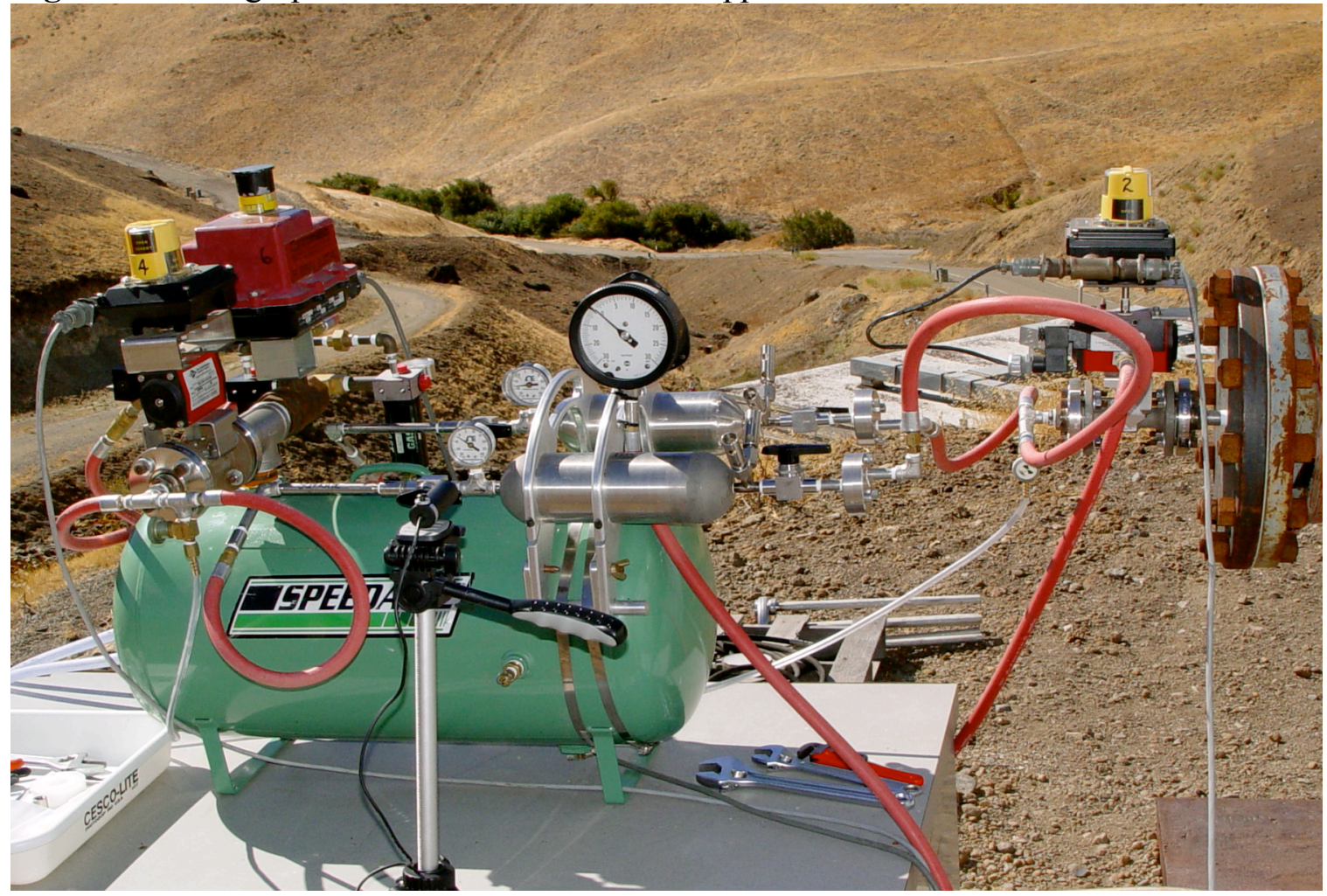


Figure 7. METS 08A Device set-up within firing tank.

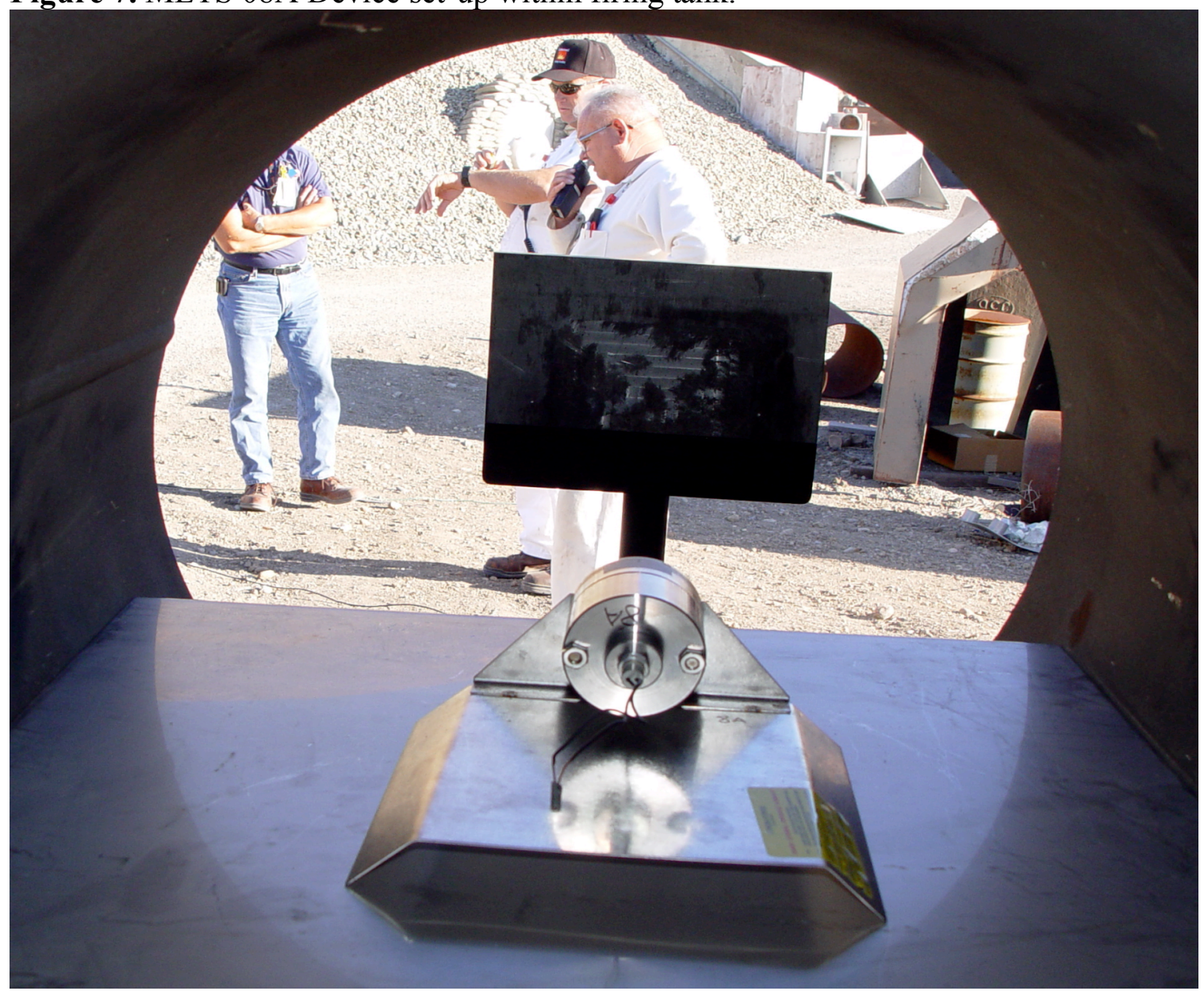

The positive SPME fiber results were then used to confirm the need for DMM approved personal protective equipment for both the retrieval of the remaining sampling train mediums. The only approved PPE material for working with DMM is Silver Shield (Blayney 2001). However, there are no fully encapsulating protective suits made from Silver Shield, so individual components were adapted to create a dermal protective clothing for the workers (Figure 8). Upon receipt of the sampling train medium results the modified PPE was utilized to open the firing tank and take bulk samples for analysis. As this process occurred during a heat wave in the late summer, the analysis of the bulk samples found that the DMM was no longer a component in the firing tank residue (Figure 9). However, the modified PPE was still worn as a safety precaution, with SelfContained Breathing Apparatus for respiratory protection (Figure 10), for firing tank clean-up utilizing an explosive-proof, pneumatic, mercury, HEPA vacuum for removing the gross debris from the tank's internal surfaces. 
UCRL-TR-223343

Figure 8. Photograph of METS 08A Silver Shield composite protective clothing.

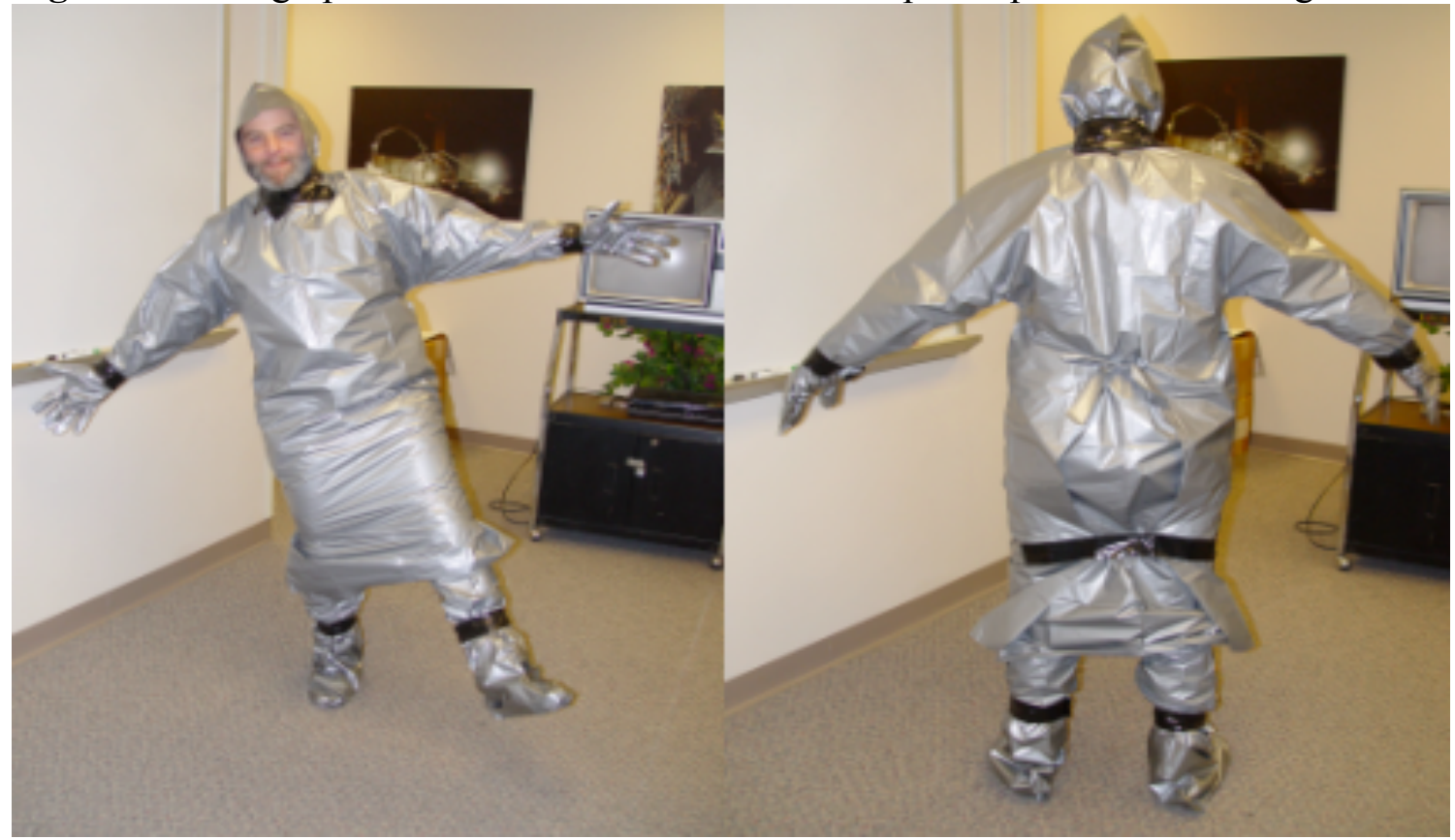

Figure 9. METS 08A post shot, before clean-up

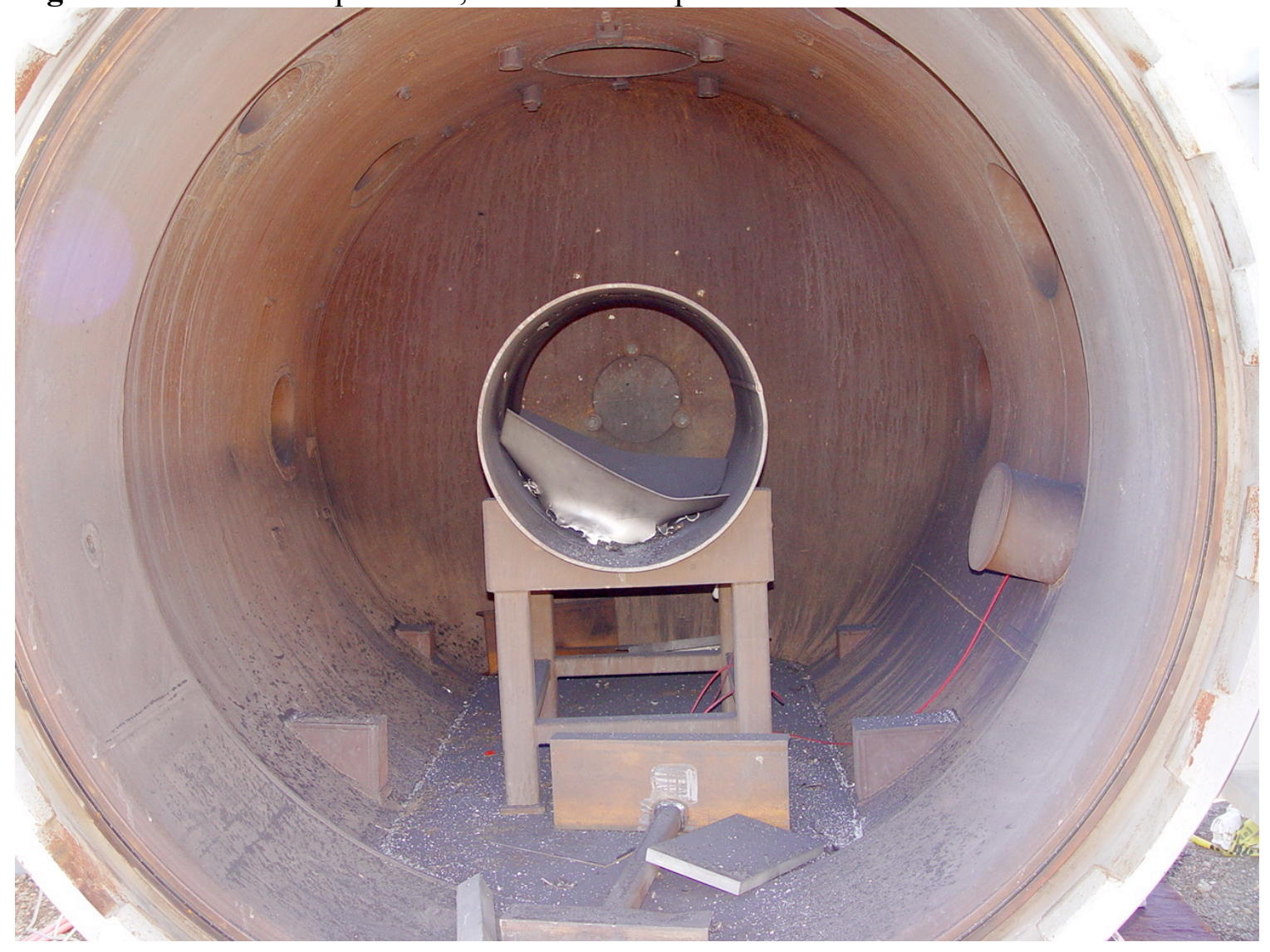


Figure 10. METS 08A firing tank clean-up

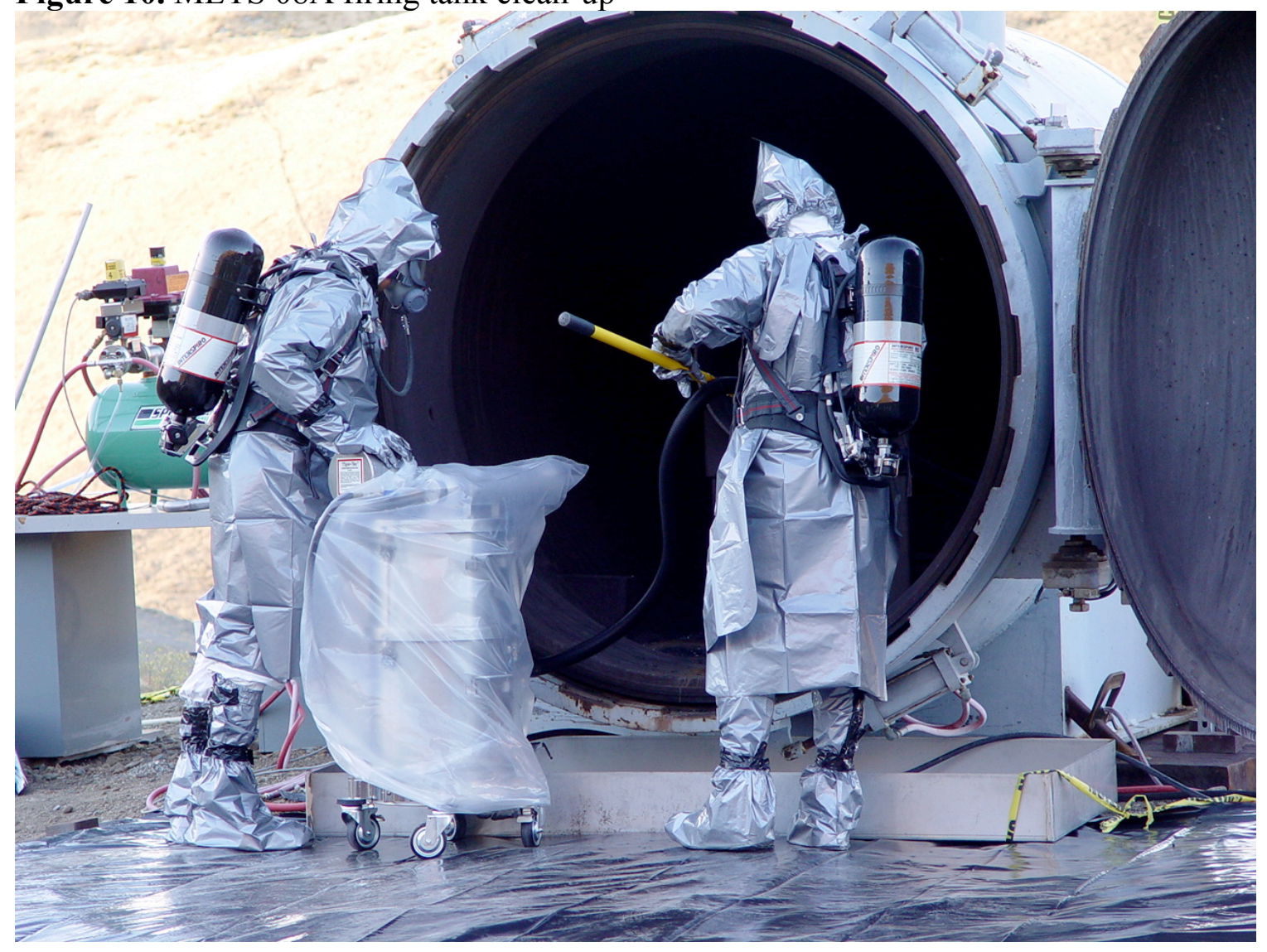

\section{METS 09A; Modify sampling apparatus, develop mitigation techniques for DMM}

With the METS 08A analysis results, the sampling apparatus was further modified. This modification included separating the sampling for the inorganic and DMM components, adding an additional trap on each line to account for potential breakthrough. Additionally, the flow was reduced to $150 \mathrm{cc} / \mathrm{min}$ to fit the specifications of the traps. The flow was controlled at a constant rate and a flow controller was added to each train to ensure this flow rate was consistent throughout the sampling procedure. We added thermocouples at the beginning and end of the train to better understand the temperatures during collection. The 1-liter sampling bottles were removed, however the fitting for the SPME fibers remained in place for static adsorption and analysis in a similar fashion to METS 08A (Figures 11 and 12).

For environmental mitigation of the DMM component after testing, but before cleaning, a method of applying heat to the tank in a manner similar to the METS 08A heat wave was implemented. This heating process utilized a heat gun to elevate the tank's internal temperature for an extended period of time to disassociate the organic mercury component. The mercury vapor created by this heating process was evacuated with the specialized vacuum previously used for clean-up. After this heating process was completed, the sampling apparatus was employed again to determine the level of inorganic mercury mitigation and to establish that the DMM component of the vapor was 
eliminated. The initial SPME fiber results from this experimental mitigation confirmed that the DMM component was below the limit of detection. With this information, the same firing tank clean-up techniques used in METS 08A were repeated for METS 09A.

Figure 11. Schematic of METS 09A collection apparatus.

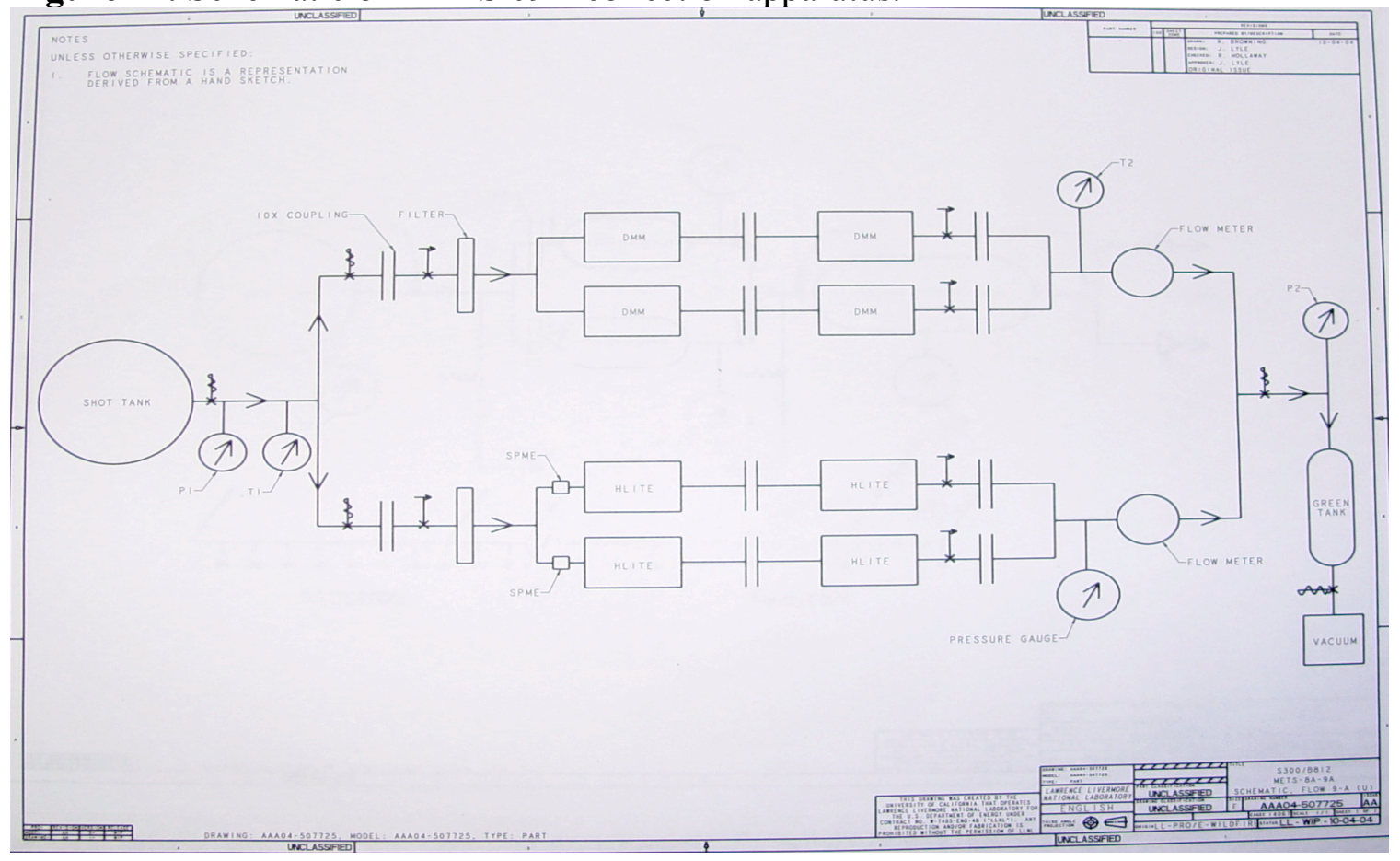

Figure 12. Photograph of METS 09A collection apparatus.

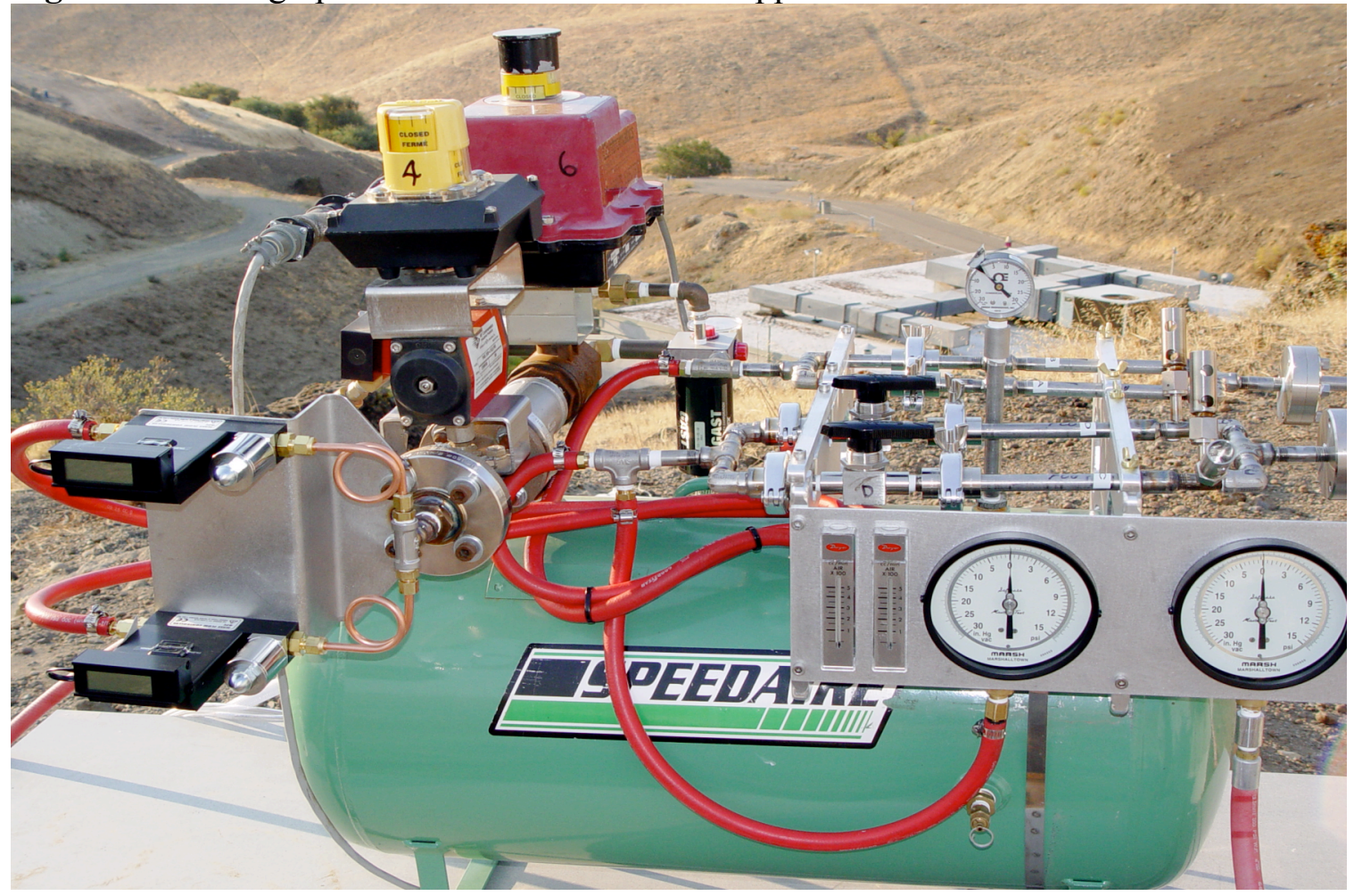




\section{Discussion}

The collection apparatus developed for METS 07 was deemed appropriate for METS 08A operations, however modifications were necessary for mercury collection. The ability to utilize the SPME fiber in the field was necessary for timeliness and accuracy, so a method to place the fiber within the tanks post shot was included within the design. Additionally, mercury sampling sorbent tubes were added to the system. The results (Table 1) from the DMM sampling techniques indicated that both DMM and organic mercury vapor were indeed created as a by-product of the experimental detonation in both METS 08A and 09A. Although attempts were made to isolate both a DMM and total organic mercury vapor content during METS 08A, the available detection methods rendered it more important and useful to focus solely on DMM as a worst-case scenario by-product for further research.

The deteriorated condition of the particulate filters and the results from the mercury sorbent tubes indicated that the rate of flow and the total volume transferred were approximately 10 times too great for the recommended flow rates of the tubes. Information was quite useful, however, for the application of a real-time inorganic mercury monitor to be used for personnel exposure potential and the creation of a safety perimeter around the tank as the organic mercury component were approximately three orders of magnitude below the inorganic mercury component. Real-time inorganic mercury levels were approximately $1 \mathrm{mg} / \mathrm{m}^{3}$ within the firing tank prior to cleaning with the bulk residue below the limit of detection for the SPME results $\left(0.5 \mu \mathrm{g} / \mathrm{m}^{3}\right)$. As air purified respiratory protection cartridges are for inorganic mercury only, a full face SelfContained Breathing Apparatus (SCBA) was used to protect the workers during cleaning to best protect the cleaning personnel.

Table 1; METS 08A post-shot results, at 1.4 liters/minute flow rate, are as follows:

\begin{tabular}{|c|c|c|c|}
\hline $\begin{array}{c}\text { Mercury } \\
\text { Component }\end{array}$ & Sample Result 1 & Sample Result 2 & $\begin{array}{c}\text { Comparison } \\
\text { Standard (ACGIH) } \\
\text { 8-hour TLV** }\end{array}$ \\
\hline DMM & $\begin{array}{c}0.5 \mu \mathrm{g} / \mathrm{m}^{3} * \\
(2 \text { hour SPME) } \\
\text { Static Load }\end{array}$ & $\begin{array}{c}0.064 \mu \mathrm{g} / \mathrm{m}^{3} \\
(20 \text { minutes, CVAAS) } \\
\text { Underestimate due } \\
\text { high flow rate }\end{array}$ & $\begin{array}{c}10 \mu \mathrm{g} / \mathrm{m}^{3} \\
\text { (as alkyl mercury) }\end{array}$ \\
\hline $\begin{array}{l}\text { Alkyl Mercury } \\
\text { (total organic } \\
\text { component) }\end{array}$ & $\begin{array}{c}\text { N/A } \\
\text { (High level of } \\
\text { hydrocarbons due to } \\
\text { SPME preference) }\end{array}$ & $\begin{array}{c}0.20 \mu \mathrm{g} / \mathrm{m}^{3} \\
\text { (20 minutes, CVAAS) } \\
\text { Underestimate due } \\
\text { high flow rate }\end{array}$ & $\begin{array}{c}10 \mu \mathrm{g} / \mathrm{m}^{3} \\
\text { (as alkyl mercury) }\end{array}$ \\
\hline $\begin{array}{l}\text { Inorganic Mercury } \\
\text { (total inorganic } \\
\text { component) }\end{array}$ & $\begin{array}{c}\text { N/A } \\
\text { (Not SPME } \\
\text { Sampled) }\end{array}$ & $\begin{array}{c}9.5 \mathrm{mg} / \mathrm{m}^{3} * * * \\
(20 \mathrm{minutes}, \mathrm{NIOSH} \\
6009 \text { by Clayton } \\
\text { Analytical })\end{array}$ & $\begin{array}{c}0.025 \mathrm{mg} / \mathrm{m}^{3} \\
\text { (as inorganic } \\
\text { mercury) }\end{array}$ \\
\hline
\end{tabular}

$* \mu \mathrm{g} / \mathrm{m}^{3} ;$ micrograms per cubic meter of air

** 8-hour TLV; 8-hour Time Weighted Average Threshold Limit Value

$* * * \mathrm{mg} / \mathrm{m}^{3}$; milligrams per cubic meter of air 
For METS 09A the sampling apparatus was modified as described above to achieve results commensurate with the sampling protocol. The results for METS 09A post-shot (Table 2) indicated a much greater level of DMM creation then for METS 08A for reasons not fully understood as the devices were ostensibly similar. There was a significant differential in temperature during shot time with approximate outdoor temperatures for METS 08A at $90^{\circ} \mathrm{F}$ and for METS 09A at $63^{\circ} \mathrm{F}$. It is presumed that the colder environment afforded better conditions for a more complete reaction of the combustion by-products. In addition there is a possibility of the reduced flow rate affording a more complete capture of the mercury vapor, with a high flow rate usually linked with a blow-by of the mercury vapor through and past the sampling tubes. The new sampling apparatus, however, was well tuned and was essential for achieving a positive link between the SPME and CVAAS analysis results from post-shot analysis.

Table 2; METS 09A post-shot results, at 0.15 liters/minute flow rate, are as follows:

\begin{tabular}{|c|c|c|c|}
\hline $\begin{array}{c}\text { Mercury } \\
\text { Component }\end{array}$ & Sample Result 1 & Sample Result 2 & $\begin{array}{l}\text { Comparison } \\
\text { Standard } \\
\text { (ACGIH) } \\
\text { 8-hour TLV }\end{array}$ \\
\hline $\begin{array}{c}\text { DMM } \\
\text { Post-Shot }\end{array}$ & $\begin{array}{c}6 \mu \mathrm{g} / \mathrm{m}^{3} \\
(2 \text { hour SPME) } \\
\text { Static Load }\end{array}$ & $\begin{array}{c}8.0 \mu \mathrm{g} / \mathrm{m}^{3} \\
(30 \text { minutes, CVAAS) } \\
\text { Estimated due high } \\
\text { DMM levels* }\end{array}$ & $\begin{array}{c}10 \mu \mathrm{g} / \mathrm{m}^{3} \\
\text { (as alkyl mercury) }\end{array}$ \\
\hline $\begin{array}{c}\text { DMM } \\
\text { Post Heat } \\
\text { Mitigation }\end{array}$ & $\begin{array}{c}<0.5 \mu \mathrm{g} / \mathrm{m}^{3} \\
(2 \text { hour SPME) } \\
\text { Static Load }\end{array}$ & $\begin{array}{c}0.20 \mathbf{n g} / \mathbf{m}^{3} * * \\
(30 \text { minutes, CVAAS) } \\
\text { Underestimate due } \\
\text { high flow rate }\end{array}$ & $\begin{array}{c}10 \mu \mathrm{g} / \mathrm{m}^{3} \\
\text { (as alkyl mercury) }\end{array}$ \\
\hline $\begin{array}{l}\text { Inorganic Mercury } \\
\text { Post-Shot } \\
\text { (total inorganic } \\
\text { component) }\end{array}$ & $\begin{array}{c}\mathrm{N} / \mathrm{A} \\
\text { (Not SPME } \\
\text { Sampled) }\end{array}$ & $\begin{array}{c}5.7 \mathrm{mg} / \mathrm{m}^{3} \\
(30 \mathrm{minutes}, \mathrm{NIOSH} \\
6009)\end{array}$ & $\begin{array}{c}0.025 \mathrm{mg} / \mathrm{m}^{3} \\
\text { (as inorganic } \\
\text { mercury) }\end{array}$ \\
\hline
\end{tabular}

* Spectrometry peaks were off scale for many seconds, missing peak values were estimated with total result ** $\mathrm{ng} / \mathrm{m}^{3}$; nanograms per cubic meter of air (CVAAS detection level is $0.22 \mathrm{ng} / \mathrm{m}^{3}$ )

During the week after the METS 09A test, a device was created to heat up the internal tank's contaminated environment. This heating process, utilizing a heat gun to elevate the tank's internal temperature for an extended period of time. The mercury vapor created by this heating process was evacuated with the specialized vacuum previously used for clean-up. The sampling apparatus was used again and determined, reflected in Table 2, that the DMM component of the vapor was effectively mitigated with a reduction of approximately four orders of magnitude to a de minimus sub-nanogram level. Analytical results for the inorganic mercury vapor mitigation, prior to clean-up, were not available at the writing of this document. However, real-time inorganic mercury monitoring indicates that the levels were approximately one to two orders of magnitude below the levels seen 
just prior to the cleaning of the firing tank during METS 08A. Specific objectives for this discussion include:

1) The DMM analytical method using the SPME fiber was determined to be, by initial results available at the time of this presentation, somewhat comparable enough to rely on and certainly within the same order of magnitude when compared to the established analytical methods used for the DMM traps.

2) The ongoing re-design of the sample collection apparatus was appropriate to ensure accurate and reproducible inorganic mercury and DMM sampling information. This design can now be controlled to adapt to varying experimental parameters to offer comparable results for determining similar constituencies.

3) The concept behind the full sampling apparatus developed is appropriate for the determination of component analyses for a variety of potential explosive tests on the four Site 300 firing bunkers.

4) This sampling apparatus is appropriate for a variety of other practical applications, including environmental fence line issues regarding PM10 limitations and Industrial Hygiene aspects of controlling exposures and determining clean-up methods for homeland security and defense program endpoints.

5) The environmental mitigation techniques for disassociating the DMM vapor and bulk component and reducing the inorganic mercury vapor concentrations aids in achieving a viable waste stream and improves conditions for manual mercury abatement. Further, eliminating the DMM in the vapor and bulk assists in using commercially available PPE to best protect the workers performing clean-up.

\section{Conclusion}

This experimental examination of the environmental, safety, health and operational aspects of experimental detonation of mercury have been successful. By creating the mechanism, sampling apparatus, and analysis techniques for post explosive by-products of mercury, the appropriate abatement techniques for cleaning the firing tank and environmental mitigation of the waste stream components have been developed. As it was discovered that DMM is indeed produced, the sampling process was entirely necessary for each step of this experimental analysis. Further, the ability to have what is now proven by this experimental process to be a reliable, quantifiable, analytical method for DMM, the SPME fiber method will afford DMM level results within approximately 4 hours from the initiation of the sampling procedure.

Determination of the by-products for personal protection equipment and exposure monitoring parameters have been achieved which assists in the ongoing nature of similar experimental work. The successful mitigation of the DMM component created in the post-shot affords the opportunity to reduce the level of respiratory protection to include 
the option of using a full face air purifying mercury cartridge with the knowledge that the organic components have been reduced by approximately four orders of magnitude. Further, elimination of DMM as a concern during clean-up expands the selection of protective clothing available for the mercury abatement personnel to include commercially available products.

\section{References}

1) Lindberg, S.E., Wallschlaeger, D., Prestbo, E., Bloom, N., Price, J., and Reinhart. (2001). Methylated mercury species in municipal waste landfill gas sampled in Florida. Atmospheric Environment 35:4011-4015.

2) Kulig, K. (1998). A Tragic Reminder about Organic Mercury. NEJM 338: 16921694.

3) Byard, R. W., Couper, R., Lockwood, A. H., Landrigan, P. J., Hanlon, D. P., Nierenberg, D. W., Blayney, M. B., Clarkson, T. W. (1998). Death after Exposure to Dimethylmercury. NEJM 339: 1243-1244.

4) Zalk, D.M. (2002), “METS 01 - 03; Beryllium Sampling." Presentation at LANL - LLNL Hydro Techniques Information Exchange, January 2002, UCRL Pending.

5) Zalk, D. M. (2001), "Metal Analysis Results for SQTS 1 - 5” ES\&H 1-01-056, UCRL Pending.

6) Zalk, D.M., Lyle, J., Arganbright, R., Simmons, L. (2003). "Metals research relating to experimental tests at CFF and Site 300". Internal LLNL presentation September 2003, UCRL Pending.

7) Koziel, J.A., Pawliszyn, J. (2001). Air Sampling and Analysis of Volatile Organic compounds with Solid Phase Microextraction. J. Air Waste Mgt Ass. 51(2): 173 184.

8) Blayney, M.B. (2001). The need for Empirically Derived Permeation Data for Personal Protection Equipment: The Death of Dr. Karen E. Wetterhahan. Applied Occ Env Hyg, 16(2): 233 - 236. 